\title{
AUTOMAÇÃO PARA O CONTROLE DA AERAÇÃO EM REATOR PILOTO PARA COMPOSTAGEM DO LODO
}

\author{
FERNANDO FERNANDES \\ SILVIA GALVÃO DE SOUZA ${ }^{2}$ \\ CLÁUDIO WALDIR NUNES ${ }^{2}$ \\ REINALDO GONÇALVES NOGUEIRA ${ }^{3}$ \\ FABIANA IZUME ${ }^{3}$
}

\begin{abstract}
FERNANDES, F; SOUZA, S.G. de; NUNES, C.W.; NOGUEIRA, R.G.; IZUME, F. Automação para o controle da aeração em reator piloto para compostagem do lodo. Semina: Ci. Exatas/Tecnol. Londrina, v. 21, n. 4, p. 89-94, dez. 2000.
\end{abstract}

RESUMO: Este trabalho apresenta a tecnologia básica desenvolvida para um reator piloto, de forma cilíndrica, de $80 \mathrm{~cm}$ de comprimento e $70 \mathrm{~cm}$ de diâmetro, hermeticamente fechado e dotado de equipamentos periféricos que permitem o total controle do processo de aeração durante a biodegradação aeróbia de substratos orgânicos no estado sólido. O controle da aeração é feito de forma automatizada através de um Controlador Lógico Programável (PLC), ligado a um micro computador, que armazena on line os dados de evolução da temperatura, vazão de ar, teor de $\mathrm{O}_{2}$ nos gases de saída do sistema e incrementos de vazão de ar. É apresentado, como exemplo, os dados de monitoramento de um experimento de compostagem de lodo de esgoto e serragem de madeira. O objetivo do piloto é permitir o estudo da biodegradabilidade de substratos orgânicos e gerar parâmetros de projeto para usinas em escala real.

PALAVRAS-CHAVE: compostagem; lodo de esgoto; automação.

\section{INTRODUÇÃO}

Compostagem é um processo de biodecomposição da matéria orgânica sob condições aeróbias. Durante o processo, a matéria orgânica original é parcialmente decomposta em $\mathrm{CO}_{2}$, água, amônia e calor. Os principais fatores que influem no processo de compostagem são: a aeração, o teor de umidade, a relação $\mathrm{C} / \mathrm{N}, \circ \mathrm{pH}$, a temperatura e granulometria (Fernandes et al., 1989), sendo que destes, a aeração e o teor de umidade são sem dúvida os mais importantes (Epstein, 1997).

De forma esquemática, o processo de compostagem pode ser representado como descrito na eq. 1 .

M. O + microrg. $+\mathrm{O}_{2} \rightarrow$ M.O estável $+\mathrm{H}_{2} \mathrm{O}+\mathrm{CO}_{2}$ + calor $+\mathrm{NH}_{3}$

\section{M.O. = Matéria Orgânica}

Alguns autores reservam o termo compostagem para a bíodegradação aeróbia, empregando o termo fermentação para o processo de biodegradação anaeróbia (Epstein, 1997). O grande fator de definição tecnológica do processo é a forma de introdução de ar durante a compostagem. Nos sistemas de leiras revolvidas o ar é fornecido através do revolvimento da massa de resíduos e da difusão, enquanto nos sistemas de leira aerada e reatores biológicos, 0 ar pode ser insuflado ou aspirado através da massa em processo de compostagem.

O controle do fornecimento de ar é um fator chave para o sucesso de compostagem (Kuter, 1995). De acordo com Haug (1986) a demanda estequiométrica de oxigênio na biodecomposição dos sólidos voláteis biodegradáveis pode ser aproximadamente calculada pelas equações abaixo.

- Para a biodegradação dos sólidos voláteis:

$\mathrm{C}_{10} \mathrm{H}_{19} \mathrm{O}_{3} \mathrm{~N}+12,5 \mathrm{O}_{2} \rightarrow 10 \mathrm{CO}_{2}+8 \mathrm{H}_{2} \mathrm{O}+\mathrm{NH}_{3}$

${ }^{1}$ Engenheiro Civil pela UNICAMP, Doutor Engenheiro pelo Instituto Nacional Politécnico de Toulouse. Professor Adjunto na área de saneamento do Centro de Tecnologia e Urbanismo, coordenador do projeto UEL no PROSAB - Programa de Pesquisa em Saneamento Básico (FINEp CNPq, MCT, CAPES, ABES). Endereço para correspondência: Universidade Estadual de Londrina, Centro de Tecnologia e Urbanismo. DCCi. Caixa Postal 6001. 86051-990 Londrina, Paraná, Brasil.

2 Bolsista PROSAB/RHAE.

3 Bolsista CNPq. 
- Para a oxidação da amônia:

$\mathrm{NH}_{3}+2 \mathrm{O}_{2} \rightarrow \mathrm{NO}_{3}+\mathrm{H}_{2} \mathrm{O}+\mathrm{H}^{+}$

- Para a decomposição de moléculas maiores como a celulose:

$\mathrm{C}_{6} \mathrm{H}_{10} \mathrm{O}_{5}+6 \mathrm{O}_{2} \rightarrow 6 \mathrm{CO}_{2}+5 \mathrm{H}_{2} \mathrm{O}$

Embora útil para a compreensão global do processo, o cálculo estequiométrico tem pouca aplicação prática, pois as misturas de resíduos a serem compostadas geralmente apresentam composição complexa e a taxa de respiração é muito variável ao longo do processo, refletindo a variação da atividade microbiológica: no início esta atividade é baixa e cresce progressivamente atingindo níveis máximos

Há uma relação direta entre a respiração microbiana e a temperatura dos sistemas em compostagem (Epstein, 1997), o que pressupõe um ritmo bem definido de fornecimento de oxigênio ao sistema para que a atividade microbiológica atinja seu nível máximo. Como a fase termófila é um objetivo importante do processo, devido seu potencial de eliminação de patógenos, o fornecimento de ar em excesso no início, pode inibir a instalação da fase termófila, enquanto que a falta de ar pode limitar a atividade biológica, impedindo a elevação da temperatura.

Outra função importante da aeração é o controle da temperatura. Vários estudos mostraram que a faixa ótima para a atividade biológica ocorre em torno de $55^{\circ} \mathrm{C}$, enquanto que temperaturas acima de $70{ }^{\circ} \mathrm{C}$ podem tornar limitantes para vários grupos de microrganismos termófilos, o que tem como conseqüência a queda geral do nível de atividade biológica e o aumento dos tempos de detenção no preparo do composto. No caso da aeração ser utilizada para controle da temperatura, uma quantidade muito maior de ar é injetado nas misturas de resíduos visando a remoção de calor. Neste caso a quantidade de ar em excesso depende do tipo de resíduo a ser biodegradado, do teor de umidade da mistura e do patamar de temperatura pretendido.

Adicionalmente, a aeração pode ser usada para secar o composto em níveis de umidade mais convenientes para sua manipulação e transporte. Neste caso as taxas de aeração podem ser até 10 vezes maiores que as necessidades de ar para suprir as demandas dos microrganismos.

Portanto o controle da aeração durante o processo de compostagem é uma variável tecnológica fundamental para o sucesso de uma usina, pois a demanda de aeração é função do tipo de resíduos a ser tratado, assim como do produto final pretendido.
Neste trabalho, é apresentada a tecnologia implantada em um reator piloto, com objetivo de automatizar os processos de aeração, durante o ciclo de compostagem. Foi utilizado o Controlador Lógico Programável (PLC), um equipamento cuja tecnologia envolvida torna possível programar atuações como ligar/desligar, temporizar, integrar, derivar, incrementar quantidades e fazer alterações no processo via software. Esta automação permite a definição de parâmetros de projeto para implantação de plantas em escala real. Como o objetivo do piloto é gerar dados científicos, ele apresenta um nível de sofisticação que não será necessário nos sistema de escala real. Por outro lado, a lógica desenvolvida para o piloto pode ser facilmente adaptada a sistemas mais simples, como compostagem em leiras aeradas. Finalmente, sendo um processo de biotransformação de resíduos, a mesma lógica pode ser adaptada para estudos de tratamento aerado de efluentes líquidos.

\section{METODOLOGIA}

$O$ reator piloto consiste de um cilindro em aço inox de $80 \mathrm{~cm}$ de comprimento e $70 \mathrm{~cm}$ de diâmetro, construído em parede dupla, espaçada de $4 \mathrm{~cm}$, cujo espaço vazio é preenchido com lã de vidro para garantir a isolação térmica da parte interna.

O cilindro é montado sobre duas hastes de metal, com plataformas, que fixam o reator e permitem que ele bascule, podendo ficar na posição inclinada para cima (carregamento), na horizontal (posição de serviço) e inclinada para baixo (descarga).

Na parte inferior interna estão fixados os difusores de ar e a sonda para medida da temperatura. $\mathrm{Na}$ parte frontal, uma tampa circular, dotada de borracha, fecha o reator hermeticamente (Foto 1 ).

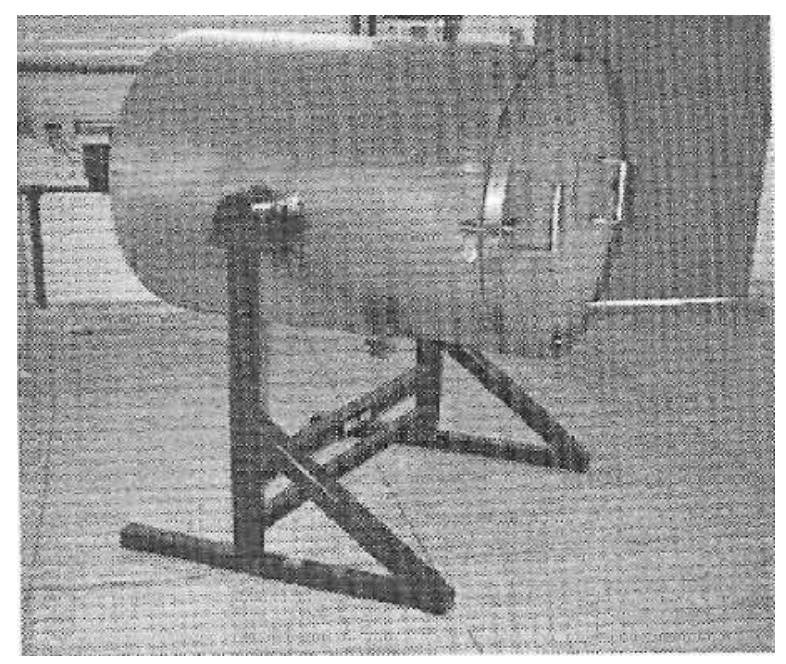

Foto 1 - Vista geral do reator piloto. 


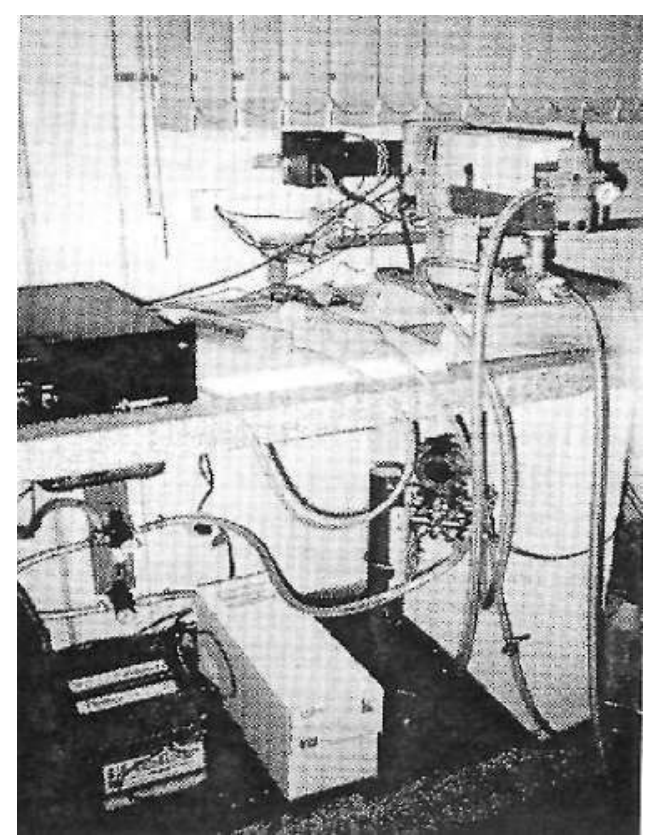

Foto 2 - Vista geral dos equipamentos periféricos logados ao reator piloto.

O sistema do reator piloto é composto pelos seguintes equipamentos (Foto 2 ):

1. O Controlador Lógico Programável utilizado é um equipamento da marca Siemens $\AA^{\circledR}$, composto por uma fonte de alimentação SITOP $\AA, 220 \mathrm{Vac} / 24 \mathrm{Vdc}$, uma CPU com 14 entrada e 10 saídas a relê digitais e um módulo de 4 entradas e 1 saída analógicas (Simatic, [19--]);

2. O software utilizado para programação do PLC é o STEP-7® - Micro/Win 16 - Siemens ${ }^{\circledR}$ (Simatic, [19-]). que permite o seu desenvolvimento através de dois módulos de programação: listagem e blocos.
3. A supervisão do sistema foi desenvolvida através do software Elipse ${ }^{\circledR}$ (Elipse..., 1998), que permite a aquisição, organização, análise dos dados e a interface do processo através de uma tela de computador, onde são mostrados os valores on-line de todas as variáveis do processo.

4. A válvula de controle de vazão do sistema faz o controle proporcional da vazão incrementando ou decrementando valores conforme a necessidade da reação biológica no interior do reator. É uma válvula tipo Varipak $\circledast$, corpo em aço inox, marca Dresser/Masoneilan $\AA$; (Posicionador..., [19-])

5. Acoplado à válvula tem-se um filtro regulador para suprimento de ar ao diafragma da válvula. (Filtro..., [19-])

6. O medidor de temperatura utilizado é uma sonda com sensor Pt 100 Din, bulbo de platina, acompanhada de um processador modelo HT 290, da Hitec $\AA$; (EroEletronic, [19--])

7. O medidor de teor de Oxigênio (Oxímetro) proporciona a medida do teor de $\mathrm{O}_{2}$ no ar através de uma célula bioquímica. Seu modelo é $100 \mathrm{~F}$ da Califórnia Analytical (Simatic, [19-]);

8. O medidor de vazão de ar, tipo Vortex integral, modelo YF101, da Yokogawa (Elipse..., [19-]);

9. Um no-break com autonomia de 2 horas, e capacidade para manter todos os equipamentos em funcionamento menos o motor responsável pelo revolvimento da mistura, e o motor do compressor de ar;

10. Compressor de ar, com capacidade de 130 litros e $5,2 \mathrm{pés}^{3} / \mathrm{min}$.

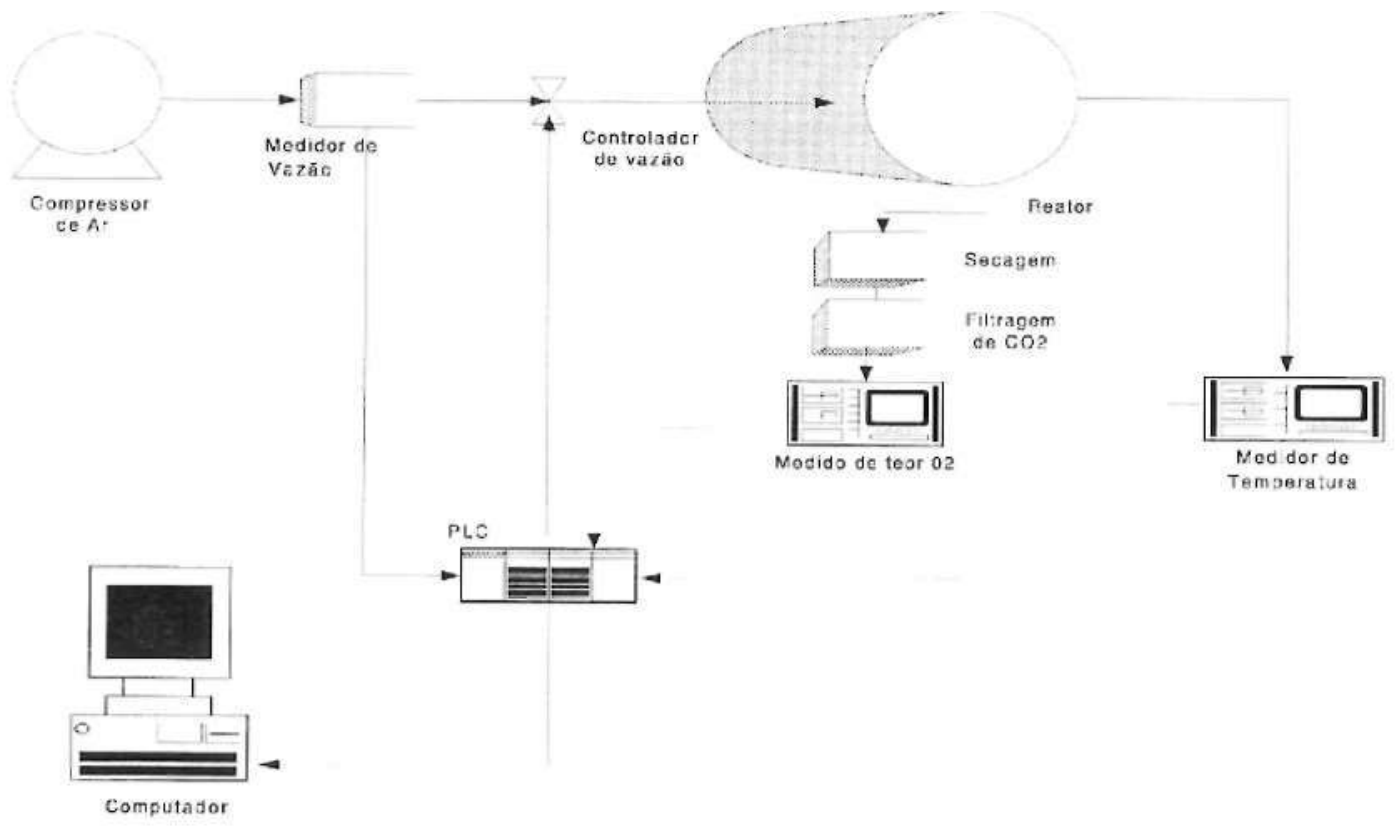

Figura 1 - Esquema de ligação do reator biológico e seus acessórios. 
11. Manômetros para o controle de pressão no medidor de vazão e na válvula de controle de ar. 12. Filtros de umidade.

A ordem de ligação pode ser vista na Figura 1.

O revolvimento do resíduo é realizado através de pás acionadas por um motor acoplado na parte traseira do cilindro. A mistura é inicialmente pesada e revolvida dentro do reator por 5 minutos. Este movimento ocorre no início do processo para efetuar o revolvimento inicial, e depois, durante a compostagem, executar revolvimentos periódicos de curta duração para desfazer eventuais caminhos preferenciais de passagem de ar.

$\mathrm{Na}$ parte inferior há uma entrada de ar que permite o acoplamento de uma mangueira, que conduz o ar. Na parte superior do cilindro, há duas aberturas, uma para a saída do ar e outra, fechada por uma rosca, que se aberta, permite a introdução de um tubo de $15 \mathrm{~mm}$ para coleta de pequenas amostras (Foto 1).

Acoplado ao reator existe um compressor de ar, que fornece o ar necessário para a reação biológica. Após o compressor é colocado um medidor de vazão. Este equipamento mede a vazão de ar controlada por uma válvula, colocada à jusante do medidor. O ar entra no reator, participa da reação e sai com teores distintos de oxigênio e $\mathrm{CO}_{2}$. Na saída do reator são colocados quatro reservatórios: o primeiro vazio tem a função de reter o excesso de umidade, o segundo com ácido sulfúrico, retém a amônia, o terceiro com $\mathrm{NaOH} 2 \mathrm{~N}$ para reter $\mathrm{O} \mathrm{C}_{2}$ e o quarto com sílica gel para retirada de qualquer resíduo de umidade. Todo o processo de retenção faz-se necessário, em função do sensor do oxímetro que sofre deterioração na presença de gás carbônico, umidade e amônia.

O medidor de vazão, o medidor de teor de oxigênio e o medidor de temperatura enviam sinais para o PLC, sendo estes os sinais de entrada do processo. A válvula de controle de ar recebe sinal do PLC, sendo este o sinal de saída do processo.

O PLC é programado através de um software dedicado. Ele é composto de uma fonte de alimentação, uma CPU, módulos de entradas/saídas digitais e analógicas. É necessária sua ligação a um microcomputador onde é desenvolvida a programação, e transferida para a CPU. Através do computador ainda é feita a supervisão do processo. O software de supervisão é o Elipse (Elipse..., 1998), proporciona uma interface amigável entre homem - máquina, o arquivamento de todos os dados do processo e a análise gráfica destes dados.

Os sinais das entradas analógicas têm variações em seus valores, muitas vezes em um pequeno intervalo de tempo, incluindo interferências internas e externas. A solução para tal fato é obtida através da filtragem deste sinal. A filtragem é o cálculo de uma média dos valores de uma amostra de quantidades pré-determinada. Esta filtragem é feita através de uma sub-rotina, que está apresentada a seguir.

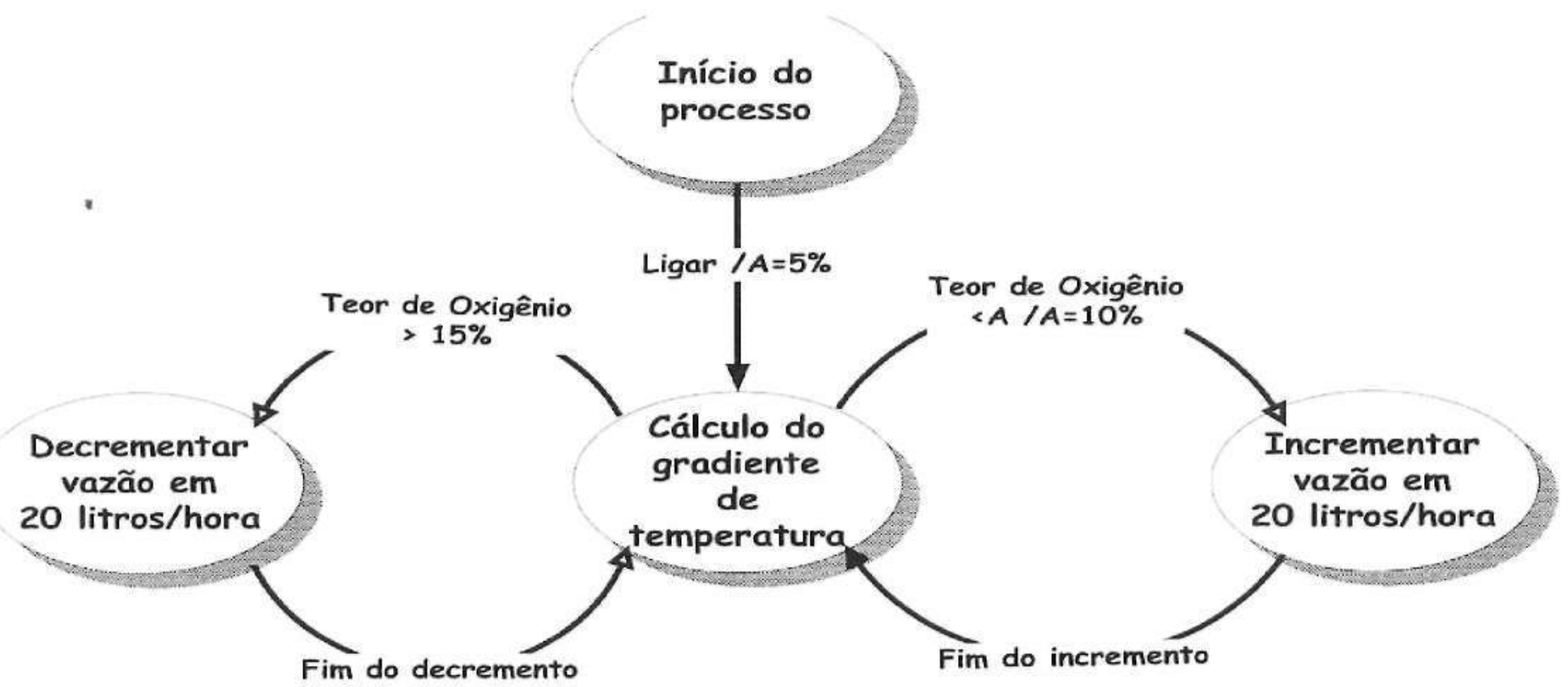

Figura 2 - Diagrama de estados do processo de compostagem. 
O processo total de controle do reator é descrito pelo diagrama de estados da Figura 2.

A forma apresentada de controle da aeração esta baseada nas necessidades de suprimento de $\mathrm{O}_{2}$ dos microrganismos, evitando-se a aeração em excesso.

Este tipo de automação permite o controle do processo de respiração microbiana e armazenamento on line dos dados de vazão, temperatura, teor de $0_{2}$ na saída do reator e incrementos de aeração.
Estes dados são armazenados através do software de supervisão, Elipse (Elipse..., 1998), que permite, determinar o intervalo de tempo a ser feito o armazenamento de cada variável, o seu formato, além de permitir que seja montada uma tela para descrição gráfica do processo, os pontos de controle e os valores das variáveis on-line.

O sistema descrito pode gerar parâmetros básicos de projeto para usinas em escala real.

Gráfico do Consumo de 02 por quilograma de Massa Seca e da Temperatura

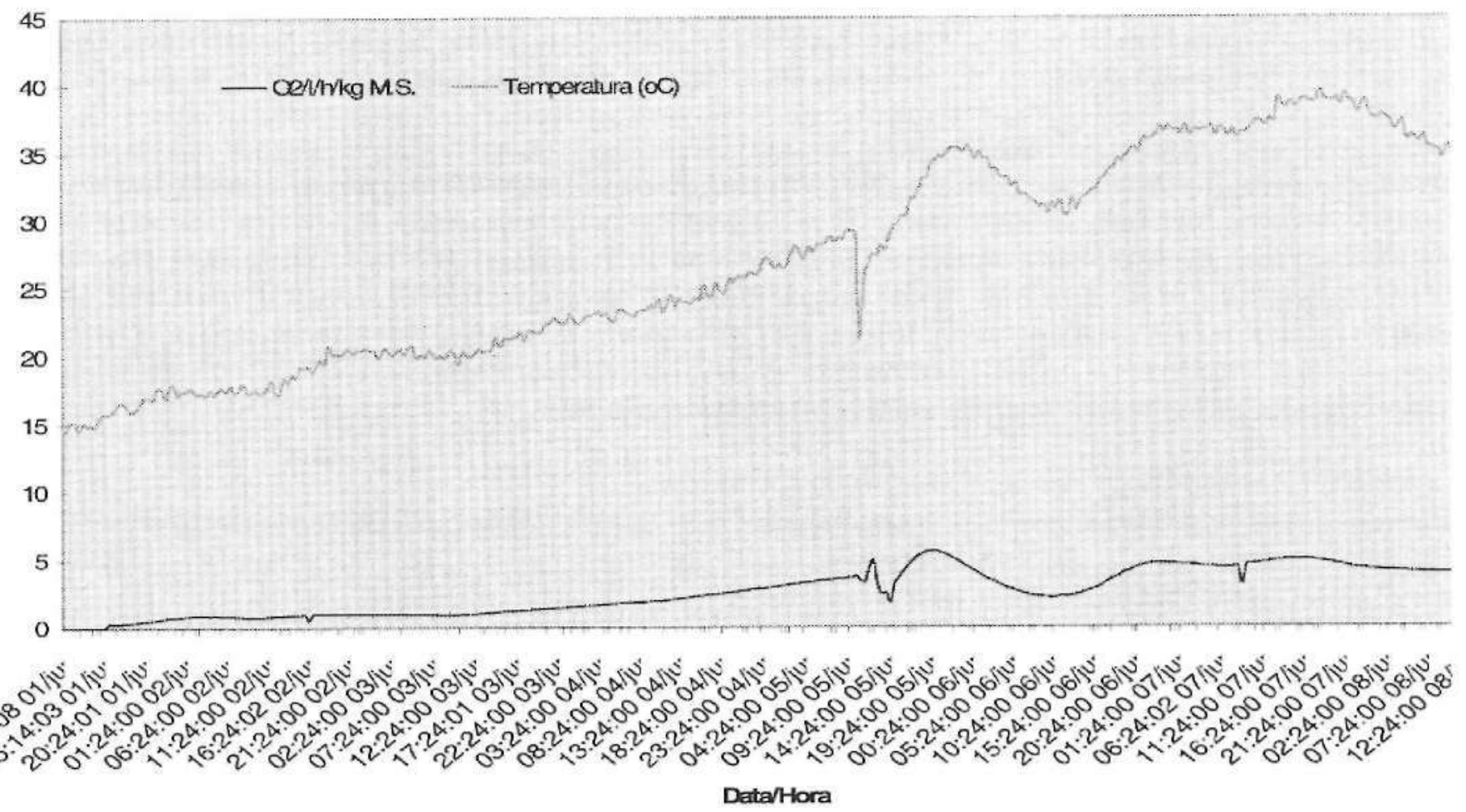

Figura 3 - Evolução da temperatura consumo de $\mathrm{O}_{2}$ na saída do reator para uma mistura de lodo de esgoto e secagem. O eixo da temperatura também indica o consumo de $\mathrm{O}_{2} \mathrm{em} \mathrm{l} / \mathrm{h} / \mathrm{Kg}$ de matéria seca.

\section{RESULTADOS}

Para uma mistura de lodo de esgotos anaeróbío, produzido em reator do tipo RALF, e serragem de madeira, são mostrados a seguir os gráficos de evolução da temperatura e teor de $\mathrm{O}_{2}$.

Observa-se uma elevação gradual da temperatura 24 horas após o início do processo e a conseqüente diminuição do teor de oxigênio no ar da saída do reator. Figura 3.

Neste exemplo, o processo foi monitorado por seis dias e interrompido após a temperatura baixar a níveis inferiores a $40{ }^{\circ} \mathrm{C}$.

\section{CONCLUSÕES PARCIAIS}

1. O exemplo mostrado neste caso apresentou ciclo termófilo bastante curto, de aproximadamente 4 dias. Mesmo assim, o monitoramento de coliformes fecais mostrou que o processo apresentou alta capacidade de desinfecção.

2. Comparado ao ciclo médio de compostagem em leiras aeradas (55 dias, para misturas semelhantes), o processo de compostagem em reator biológico apresenta grande redução do tempo de estabilização e tota! controle de odores.

3. Mesmo considerando os problemas técnicos 
encontrados nos equipamentos periféricos e no próprio reator, o equipamento esta operacional e mostraque tem amplas possibilidades de controle do processo de respiração microbiológica, abrindo perspectivas para uma ampia linha de pesquisas, voltadas para o estudo da biodegradabilidade de ampla gama de substratos orgânicos, assim como para a determinação de parâmetros de projeto para usinas de compostagem bem adaptadas às características dos resíduos a serem tratados.
4. Outra forma de controle, usando este sistema tomar como parâmetro a temperatura da mistura e regula a vazão de ar com incrementos constantes até a temperatura atingir o patamar desejado. Neste caso, o fornecimento de ar será bem maior do que o necessário à respiração microbiana.

5. Também é possível, inserir na massa de resíduos uma sonda para medida de umidade, e assim variar a aeração até atingir a umidade desejada.

FERNANDES, R; SOUZA, S.G. de; NUNES, C.W.; NOGUEIRA, R.G.; IZUME, F. Automation for aeration control in pilot reactor for sludge composting. Semina: Ci. Exatas/Tecnol. Londrina, v. 21, n. 4, p. 89-94, dez. 2000.

ABSTRACT: This paper presents the basic technology developed for a cylindric pilot reactor with $80 \mathrm{~cm}$ long and $70 \mathrm{~cm}$ of diameter. The reactor is a closed system, equipped for total control of the aeration process during the aerobic degradation of the solid organic residues. The automatisation of air flow is done by a PLC, connected to a computer which stores data on temperature, air flow, 02 level in exit gases and increments of air flow. As an illustration, the data of an experiment using sewage sludge and wood residues, are presented. The purpose of this pilot reactor is to study the biodegradability of organic residues and to determine project parameters for real scale composting plants.

KEY WORDS: composting; sewage sludge; automation.

\section{REFERÊNCIAS BIBLIOGRÁFICAS}

ELIPSE Windows, Supervisory Control and Data Acquisition System - Elipse Software Ltda - Manual do usuário, 1998.

EPSTEIN, E. The science of composting. Lancaster (USA): Technomic Publishing Company1997. 487p.

EroELETRONIC - Manual do usuário - LFS - $\mathrm{mA}$, ref. 170.IUO.LFS.MAO - 1.7-97., revendedor Hitec.

FERNANDES, F.; VIEL, M.; SAYAG, D.; ANDRÉ, L. Microbial brekdown of fats through In-vessel co-composting of agricultural and urban wastes. Biological wastes, n. 6, p. 33$48,1988$.

FERNANDES, F.; SILVA, S. M. C. P. Manual prático de compostagem de biossólidos. Rio de Janeiro: Ed. FINEPPROSAB, 1999. 84p.

FILTRO regulador $77-4$ - Válvula Reguladora para suprimento de ar-Instruções e relação de peças, Masonelan, ref. 1044PPSI.

HAUG, R.T. Composting process design criteria: parts 1-4. Biocycle, n. 27 , p.8-25, 1986.

INSTRUCTION Manual, Model 100 Oxygen Analyzer California Analytical Instruments, Inc.

KUTER, G. A. Biosolids composting. Alexandria (USA): Water Environmental Federation, 1995. 187 p. Special publication.

MANUAL de Instruçāo; Modelo EJA 115, Low Flow Transmitter, ref. manual 22E, IM 1C22K1-01E.

POSICIONADOR Eletro-Pneumático, Masonelan - Modelo 8013, Instruções, ref. ES 5000.

SIMATIC, Sistema de Automação, S7-200, manual do sistema, ref. 6ES7298-8FA01-8DHO. 